\title{
BREVE ANÁLISIS DE LA APLICABILIDAD DE LA LEY 342 A LA REALIDAD SOCIAL PUERTORRIQUEÑA
}

Gloria M. Molina'

B asado en nuestra experiencia profesional como trabajadora social y profesora, deseamos compartir algunos hallazgos, comentarios e interrogantes que tenemos al experimentar la aplicación de la Ley 342 del 16 de diciembre de 1999, denominada como la Ley para el Amparo de Menores en el Siglo XXI. La misma deroga la anterior Ley 75 del 28 de mayo de 1980, según enmendada, conocida como Ley de Protección de Menores. Reconocemos que ésta es una ley nueva, que tiene poco tiempo de existencia; sin embargo, consideramos necesario plantear las críticas tanto positivas como negativas desde un enfoque de aprendizaje y mejoramiento. Es de todos sabido que dicha Ley responde a unas presiones que ejerciera el Gobierno Federal para que la misma se ajustara y respondiera a la ley establecida por éste en los Estados Unidos. Es así que se promueve la derogación de la Ley 75 y se inicia una nueva ley sin la divulgación suficiente de la misma. Entendemos que uno de los grandes fallos de un proyecto es tratar de implantarlo sin darle oportunidad a los diversos sectores a participar en la confección y divulgación del mismo. Veamos un poco de

\footnotetext{
${ }^{1}$ Catedrática, Escuela Graduada de Trabajo Social Beatriz Lassalle, Universidad de Puerto Rico.
} 
la ya historia. El 14 de octubre de 1999 fue radicado en la Legislatura el Proyecto de la Cámara de Representantes Número 2840, que sirvió de base a esta ley; luego, durante el mes de noviembre se celebraron las acostumbradas vistas. El 16 de diciembre de 1999 ya el proyecto se había convertido en ley y para el 15 de marzo de 2000 se estaba implantando.

Hemos narrado esta pequeña historia para ponernos en perspectiva del corto tiempo que transcurrió entre la idea, el proyecto, la ley y el proceso de implantación de la misma que todavía no ha concluido en su totalidad. En ese período de tiempo no ocurrió algo tan necesario como lo es la educación y divulgación de la ley y el análisis de las implicaciones de su implantación. Era imprescindible que profesionales de ayuda, tales como trabajadores sociales, psicólogos, orientadores, consejeros, entre otros, así como otros profesionales como psiquiatras, médicos, jueces, enfermeras, conocieran a cabalidad los estatutos de la ley. La realidad es que esto no se dio. Y aún el pueblo, la gente, los padres/madres a quien se les iba a aplicar el peso de la ley, desconocían la misma y todavía hoy en día son muchos los que aún se extrañan de su existencia cuando se les habla de la Ley 342. En el Informe que el Colegio de Abogados sometiera a la Comisión de lo Jurídico Civil de la Cámara de Representantes sobre este Proyecto de ley (\#2830, o sea, antes de convertirse en Ley), se estableció claramente la posición en la cual recomendaban que no se aprobara esta trascendental medida en la sesión legislativa que concluía en el mes de noviembre de 1999 (Villanueva Muñoz, 1999).

El Colegio de Abogados solicitaba que el proceso de estudio sobre este proyecto se debía extender por más tiempo y establecieron que: "la prisa no es buena consejera en la aprobación de legislación de mucha trascendencia social, como es el proyecto en cuestión, pues se refiere a los menores, tesoro humano del país". Además, expresaron claramente que: "la experiencia enseña que se ha tenido que prorrogar la vigencia de legislación aprobada aceleradamente" (Villanueva Muñoz, 1999). Estos señalamientos del Colegio de Abogados no fueron escuchados. Además, no se ha seguido la recomendación realizada por la Sra. E. González, Directora del Hogar Cuna San Cristóbal, para evitar que esta Ley sea inoperante. Ésta establece que "es importante desarrollar una campaña intensa en todos los medios de comunicación del país, para la divulgación de la misma, orientando sobre todos sus componentes y su impacto 
en la familia puertorriqueña" (González, 1999). Según ésta plantea, "es necesario que la comunidad entienda, asimile, e internalice los alcances de la misma (ley) para que comience a trabajar de forma terapéutica con su propia familia y evitar su desintegración. Esta campaña puede constituir la primera etapa de los mencionados esfuerzos razonables" (González, 1999). Considero que todavía no es tarde para comenzar a ejecutar estas excelentes recomendaciones.

Conozcamos las intenciones y los propósitos de la ley 342. Estos van dirigidos a:

1. Re-enfocar la política pública de protección a menores (enfocando primordialmente el mejor bienestar del menor y que el derecho a la unidad familiar está limitado por el derecho que el menor tiene de ser protegido del maltrato y la negligencia).

2. Establecer las normas que rigen los procesos administrativos y judiciales.

3. Facilitar la coordinación entre las agencias y entidades que ofrecen servicios a los niños maltratados.

4. Facultar al Departamento de la Familia a implantar la Ley (En la Ley 75 era también el Departamento de la Familia la agencia responsable de implantar la Ley. En la actual Ley el proceso de implantación está en camino).

5. Incluir a los menores bajo su tutela en el sistema de búsqueda de hogares adoptivos en Puerto Rico y en otros estados y territorios de Estados Unidos.

6. Crear los cargos de Procuradores de Familia Especiales para situaciones de maltrato, maltrato institucional, maltrato por negligencia y maltrato por negligencia institucional.

7. Tipificar los delitos de maltrato y/o maltrato institucional, maltrato por negligencia y/o maltrato por negligencia institucional.

8. Imponer penalidades. 
Reconocemos que el espíritu de la Ley está dirigido al mejor bienestar del menor. Creemos fielmente que la inestabilidad y la falta de permanencia de los/as niños/as son contrarios al mejor bienestar del menor. Es indispensable velar porque los/as niños/as logren un mejor desarrollo dentro de un ambiente seguro y positivo. Los/as niños/as que muchas veces son movidos de un hogar a otro se les priva de establecer relaciones consistentes con figuras significativas para su desarrollo. Además, se les hace imposible identificarse con un tipo de familia y "echar raíces", lo cual puede repercutir en su futuro comportamiento. Es así que la nueva Ley establece muy claro desde su Exposición de Motivos que la política pública busca proteger al menor por encima de cualquier otra consideración (Nevares de Rosselló, 1999).

Claramente la ley estipula que es el Estado el responsable de intervenir para proteger la salud y bienestar de un menor cuando los padres de éstos no pueden satisfacer sus necesidades o protegerlos adecuadamente. Definitivamente, esta ley le ofrece más agilidad al Estado para intervenir en la remoción de un niño de su hogar. También le otorga mayores poderes al Estado para quitarle la patria potestad a los padres/madres que maltratan a sus hijos/as y facilita la adopción permanente de estos menores (Santana, 1999). En este sentido limita los esfuerzos que se realizaban bajo la Ley 75 para reintegrar una familia a la que se le han quitadolos/as hijos/as por razones de maltrato. En otras palabras, la Ley 342 promueve que un/a padre/madre que repetidamente está maltratando a el/la hijo/ a, no se le vuelve a entregar el/la menor y que los vínculos entre éste se terminen y rompan. Es así que los progenitores pierden la patria potestad y su prole pasa a formar parte de una lista para ser adoptados tanto en Puerto Rico como en Estados Unidos y sus territorios. Según la Sra. E. González, Directora del único albergue en Puerto Rico para niños en transición de adopción, "el grupo de niños candidatos a adopción que confronta serias dificultades para ser adoptados son niños mayores de cuatro años y con necesidades especiales (González, 1999). La experiencia refleja que las personas desean adoptar niños pequeños, preferiblemente recién nacidos, que gocen de una buena salud física y emocional, y que tengan un buen comportamiento. La mayoría de los/as niños/as que sufren del maltrato y negligencia no poseen las características descritas anteriormente. En su gran mayoría, los menores que han experimentado actos de violencia familiar, ya sea contra ellos (maltrato 
físico y/o emocional) o hacia otros en el seno familiar, presentan problemas de conducta. Esto puede deberse a varios factores, como por ejemplo: al aprendizaje a través del modelaje que han obtenido, o por rebeldía de su parte o simplemente porque no conocen medios apropiados y aceptables de comportamiento. En Puerto Rico la gran mayoría de los/as niños/as que son elegibles para adopción han sido removidos de sus hogares por ser víctimas de maltrato (Rodríguez-Burns, 2002).

Las estadísticas del Departamento de la Familia reflejan que en Puerto Rico en los últimos años ha habido una tendencia de más adopciones, de 297 en el año fiscal 1990-91 a 451 en el 2000-2001 (Rodríguez-Burns, 2002). Aún así, algunos profesionales de la conducta humana reconocen que existen varias dificultades en los procedimientos de adopción, lo cual imposibilita que muchas de estas no se concreticen. Por ejemplo, el exceso de burocracia en los procedimientos de adopción y la lentitud en el proceso podrían mencionarse como dificultades sobresalientes. Estos factores afectan ya que los/as niños/as van creciendo mientras se dan estos procedimientos de adopción, y los candidatos a ser padres adoptivos no desean adoptar a niños/as mayores (Rodríguez-Burns, 2002). Aún así, debemos reconocer que el Departamento de la Familia está realizando esfuerzos para agilizar los procedimientos de la adopción. Dicha agencia admite que las adopciones en Puerto Rico podrían tardarse más de uno a dos años (Rodríguez-Burns, 2002). Un factor determinante es el proceso de liberación de los/as menores, o sea, privar la patria potestad a los padres. La Ley 342 estipula que se cuenta con un tiempo máximo de un año para determinar el futuro de los menores. La realidad es que también se tiene que considerar que tanto la Oficina del Procurador del Menor como los Jueces juegan un papel decisivo en la determinación final de lo que se hará con el/la menor. El procedimiento para una familia adoptar conlleva, entre otros aspectos, lo siguiente:

- Recibir una orientación y un formulario con los requisitos en la Oficina del Programa de Adopción.

- Cumplir con los siguientes requisitos: documento médico completado, certificado de buena conducta, evidencia de ingresos, planillas, carta del patrono, tres cartas de recomendación, entre otros documentos. 
Estudio social del candidato o candidatos realizado por el Departamento de la Familia. A la/s persona/s se le exige "solvencia moral" y "reputación intachable". La agencia asegura que no toma en consideración la preferencia sexual del candidato o su estatus civil.

Luego de completar estos requisitos, resta esperar que termine el proceso de ubicación de un/a niño/a en un hogar adoptivo aunque la agencia asegura que éste puede durar de seis meses a un año. Tenemos la esperanza de que el Departamento de la Familia ponga gran empeño en agilizar este proceso para el mejor bienestar de los/as niños/as de nuestro país.

Por otro lado, un aspecto significativo de la Ley 342 es que tipifica los delitos de maltrato y/o negligencia, inclusive el incurrido por instituciones, tanto gubernamentales como privadas. Aún así resulta confusa la tipificación como delito de las manifestaciones del maltrato, maltrato por negligencia, maltrato institucional y maltrato por negligencia institucional (Rivera Watterson y Marrero Aulet, 1999). La Ley no cualifica en términos de frecuencia, magnitud y alcance de las distintas modalidades y maltrato, y cuáles de éstas constituirán delito (Rivera Watterson y Marrero Aulet, 1999). Sin embargo, es por primera vez que se establecen penalidades para aquéllos que maltratan a un menor. En otras palabras, se castiga al que incurra en maltrato y/o negligencia hacia un/una menor. Esto representa un enfoque de prevención a nivel terciario; o sea, se trabaja, se interviene cuando ya tenemos el problema en nuestras manos (Pransky, 1980). La mayoría de los fondos económicos van dirigido a intervenir con el problema. Debemos detenernos un momento y cuestionarnos: "a la larga, ¿no sería menos costoso si educamos a nuestra gente y le proveyéramos del desarrollo de destrezas de crianza?” Es imperativo que la política pública dirija más esfuerzos a la prevención primaria. La pregunta sería: ¿cómo? Pues, a través de radicación de proyectos de ley, que enfaticen la necesidad de padres/madres de recibir adiestramiento (a través de talleres o grupos de apoyo) sobre alternativas de manejo de disciplina sin incurrir en el maltrato y la negligencia, además que éstos reconozcan su responsabilidad y deberes como progenitores. Recordemos que no sólo con "castigo" podemos erradicar el maltrato en Puerto Rico. 
Entre los puertorriqueños tenemos un refrán que dice: "una de cal y otra de arena"; y efectivamente, aplicando éste a la Ley 342 no todo es negativo, pues como hemos visto, ésta presenta también algunos aspectos muy positivos. Uno de estos que reconocemos es lo que se plantea en el Artículo 34 de la ley. Este se relaciona con los informes infundados, o sea, aquella información que carece de fundamento para sustanciarla. Dicho Artículo establece que “...el Departamento podrá imponer una multa, que no excederá de $\$ 10,000$ (diez mil dólares) por cada violación a cualquier persona que voluntariamente y a sabiendas ofrezca información falsa que constituya un informe infundado de maltrato, maltrato institucional, maltrato por negligencia y/o maltrato por negligencia institucional o aconseje a otra para que lo haga. Cada vez que se ofrezca un informe infundado o se aconseje a otra persona para que lo haga constituirá una violación independiente." Aún en este momento este artículo no se ha implantado. Son muchas las historias que hemos escuchado de personas que hacían y hacen mal uso de el recurso de informar sobre aún la mera sospecha de maltrato hacia algún menor. Sabemos de personas que informaban y reportaban con propósitos personales de actuar en contra de otro adulto, ya sea por coraje contra éste o resentimiento o por desquitarse de algo que la persona pudiera haberle hecho. Esto se ha observado entre parejas que están atravesando una separación, divorcio o tienen un pleito legal de custodia de sus hijos/as. Entendemos que el Artículo 34 de la Ley representa una medida para que las personas tomen conciencia de las implicaciones de sus acciones al hacer mal uso de los referidos y la información carente de fundamentos (Rodríguez, 1999). Sin embargo, si miramos la otra "cara de la moneda", este Artículo también puede limitar a las personas a dar información o referir por temor a que se les aplique la multa.

Otro aspecto positivo de la Ley es que establece un término de tiempo máximo de seis (6) meses para que tanto los padres o personas responsables por el bienestar del/la menor como el Departamento de la Familia ejecuten las medidas necesarias a fin de que el menor pueda regresar a su hogar en el plazo de tiempo más breve o que se tomen las providencias que sean necesarias para una determinación final sobre la custodia del menor. Implica, pues, que tanto los padres o encargados y el Departamento de la Familia tienen que llevar a cabo todos los "esfuerzos razonables", o sea, es responsabilidad del Departamento de la Familia de diseñar, establecer, crear 
o solicitar servicios y actividades encaminadas a:

- evitar la remoción de los/as menores

- reunificar a la familia si los/as menores han sido removidos/as

- lograr una familia permanente para un/a menor cuando su familia biológica ha sido descartada.

Por otro lado, es también responsabilidad del padre/madre o persona encargada del/la menor de ejecutar, o sea, poner en acción todo lo establecido en el Plan de Trabajo por el representante del Departamento de la Familia. Es así que en un máximo de seis (6) meses, una vez ha ocurrido la remoción y se priva al padre/madre de la custodia en forma provisional, que se tienen que agotar todos los "esfuerzos razonables" existentes para reubicar a el/la menor con su padre/madre biológico o encargado. Tenemos que destacar que la Ley estipula claramente las situaciones específicas en las cuales no se harán "esfuerzos razonables" previos a la remoción de un menor de su hogar. En resumen, éstas son:

1. Si el adulto responsable por el bienestar del menor sufre de una incapacidad o deficiencia mental y la misma es de tal magnitud que le impide cuidar y proteger adecuadamente al menor.

2. Si el/la menor ha sido removido/a del hogar (antes de haberse aprobado esta Ley) y se había ubicado nuevamente al/la menor en su hogar y este/a menor es nuevamente víctima de maltrato.

3. $\mathrm{Si}$ el/la menor ha sido previamente removido/a.

4. Si el padre y la madre han sido privados de la patria potestad respecto a otros de sus hijos/as y no han pedido resolver los problemas que le causaron la pérdida de la patria potestad.

5. Si el padre/madre o encargado del/la menor ha causado daño físico o ha puesto en riesgo la salud, integridad física, mental, emocional y/o moral del/la menor.

6. Si el padre/madre o persona responsable del bienestar del/la 
menor incurre en conducta que constituye delito contra la salud e integridad física, mental, emocional y/o moral del/la menor, su padre/madre o hermanos (según el Código Penal del ELA).

7. Si el padre/madre o persona responsable del bienestar del/la menor incurre en conducta que constituye delito al ayudar, intentar, conspirar, solicitar o aconsejar a la comisión de delitos que atenten contra la salud e integridad física, mental, emocional y/o moral del/la menor, su padre/madre o hermanos (según el Código Penal del ELA).

8. Si el padre/madre o persona responsable por el bienestar del/ la menor incurre en conducta obscena, según definida en el Código Penal del ELA.

Por otro lado, la Ley también estipula que no se harán "esfuerzos razonables" para reunir a un/a menor con su padre/madre o persona responsable de su bienestar si ocurrieran, en resumen, las siguientes situaciones:

1. Si los esfuerzos establecidos para el cambio no han sido exitosos luego de seis (6) meses de haberse iniciado.

2. Si el padre/madre o persona responsable del bienestar del/la menor ha expresado no tener interés en la reunificación del/ la menor.

3. Si el padre/madre o persona responsable del bienestar del/la menor sufre de una incapacidad o deficiencia mental de tal magnitud que le impide beneficiarse de los servicios de reunificación. Ciertamente esto se tiene que demostrar con evidencia científica provista por un psicólogo o psiquiatra donde se señale la incapacidad de éstos de cuidar adecuadamente al/la menor.

4. Si antes de la aprobación de esta Ley el/la menor había sido previamente removido/a por haber sufrido daño físico o abuso sexual en el núcleo familiar y luego de habérsele adjudicado la custodia del/la menor a éstos, y el/la menor es nuevamente removido/a. 
5. Si el padre/madre habían sido privados de la patria potestad respecto a otros hijos/as y no habían podido resolver los problemas que causaron la pérdida de la patria potestad, a pesar de los servicios prestados.

6. Si el padre/madre o encargado del menor incurre en conducta, que de procesarse por vía criminal, constituiría delitos contra la salud, integridad física, mental, emocional y/o moral del menor, su padre madre o hermanos.

7. Si padre/madre o encargado incurre en conducta de ayudar, intentar, conspirar, solicitar o aconsejar a la comisión de delitos que atentan contra la salud e integridad física, mental, emocional y/o moral del menor, su padre, madre o hermanos.

8. Si padre/madre o encargado/a incurre en conducta obscena.

9. Si el menor bajo la custodia legal del Departamento de la Familia por el padre/madre o encargado/a presenta un problema crónico de abuso de sustancias controladas y el diagnóstico establece que los menores no pueden regresar a su hogar en un período de seis (6) meses.

La experiencia que hemos tenido en el Proyecto "Homebuilders" - Reunificación del Programa de Apoyo Familiar a Niños y Adultos (AFANA) de Mayagüez es que si se dan unas circunstancias específicas, se podría lograr determinar el destino de un menor, ya sea la reunificación (volver al hogar biológico) o a un hogar adoptivo permanente. El tiempo que establece la ley es de seis (6) meses; sin embargo, deben prevalecer las siguientes circunstancias:

1. Que el trabajador social o técnico que intervenga en la situación no tenga más de un volumen de cinco a ocho situaciones de protección asignadas. Es ardua la tarea que hay que llevar a cabo en las situaciones de esta índole, desde el desarrollo en los progenitores de destrezas en el manejo de disciplina, cuidado y supervisión de los menores, coordinar y supervisar visitas familiares, hasta coordinar servicios para la familia, entre otras. Es un proceso de intervención que incluye entre otros aspectos lo siguiente: 
a) el establecimiento de la relación profesional con la familia (lo cual a veces se hace difícil, ya que la agencia que está facultada por ley es la que remueve a sus hijos/as y la que a la vez le va a prestar unos servicios, y esto podría llevar a que surja mucha desconfianza por parte de la familia);

b) diseño y discusión del contrato de servicios el cual incluye el plan de servicios (basado en la identificación de necesidades, intereses y problemas) y compromiso de todos los componentes involucrados en la situación;

c) ejecución del plan de servicios, tanto de parte de la familia como del trabajador social o técnico responsable de la situación;

d) evaluación progresiva del Plan de Servicios y examen de los posibles inconvenientes que no permiten el cumplimiento del Plan;

e) preparación del informe al Tribunal con sus respectivas recomendaciones basadas en los resultados del Plan de Servicios estructurados; $y$

f) participación del trabajador social o técnico en la vista del Tribunal.

A veces una familia asignada se puede convertir en dos (2) o más familias, como por ejemplo, cuando ésta es una reconstituida o compuesta de familia nuclear con extendida. Por tal razón se complica, aún más, la labor y tarea del trabajador social o técnico. Es por tal motivo que este profesional tenga asignado a su cargo entre cinco a ocho situaciones concurrentemente para así garantizar un servicio de excelencia en el proceso de intervención.

2. Que se logre una mayor coordinación y participación de otras agencias en el proceso de intervención. A pesar de que la ley estipula claramente en el Artículo \#22 que: “todas las agencias del Gobierno de Puerto Rico estarán obligadas a conferirle prioridad a las situaciones de maltrato", estipuladas en la Ley y además tienen la obligación de "coordinar entre sí 
sus esfuerzos cuando se requiera la prestación de servicios relacionados con la identificación, prevención o tratamiento de los menores que son víctimas de maltrato...", la realidad es que dichas agencias no responden en muchas ocasiones al reclamo que hace el trabajador social o técnico en pro del mejor bienestar del niño/a y su familia. El mismo Dr. Víctor I. García Toro, Administrador de ADFAN, reconoció que el Departamento de la Familia no ha logrado recabar la ayuda de las demás agencias del Gobierno en la lucha contra el maltrato de niños/as (Torres Gotay, 2001). Considero que es limitada la ayuda que han ofrecido algunas agencias y creo que se debe de ser más "agresivo" en el empeño por involucrar a todas las agencias en el proceso de intervención. Como parte de las vistas públicas de esta ley la Dra. Angélica Varela, Secretaria del Departamento de la Familia para ese entonces, reconoció "la responsabilidad de todas las oficinas, componentes operacionales del Departamento y de todas las agencias del gobierno la obligación de conferirle prioridad a las situaciones de maltrato" (Varela, 1999).

En mi experiencia he podido palpar la angustia de dos (2) familias que han cumplido con todo el Plan de Servicios; sin embargo, no han de recibir a sus hijos/as en su hogar porque las condiciones del mismo están deplorables (vicios de construcción o estructura que refleja una extrema pobreza). En la búsqueda de un hogar apropiado, estas familias se han enfrentado a todo el proceso burocrático de las agencias pertinentes, que muchas veces los ponen en una lista de espera que puede durar más de dos años antes de que llegue su turno. Mientras tanto, ¿qué sucede con sus hijos/as? ¿Son acaso estas familias víctimas también de un sistema mayor? Es triste ver la desilusión y frustración de dichas familias que a pesar de cumplir con todo lo estipulado en su plan de servicios y haber logrado todos los "esfuerzos razonables" no poseen el control de tener una vivienda adecuada para el retorno de su prole y la estabilización familiar. Los progenitores o encargados de los/as niños/as pueden tener la mejor disposición y el mayor interés en que los/as niñas regresen al hogar, pero muchas veces el ambiente no provee los recursos necesarios e indispensables para lograr esto. 
3. Que se adiestre al personal profesional no sólo en el área cognoscitiva, sino también en el desarrollo de destrezas tales como: asertividad, toma de decisiones, solución de conflictos, intervención en situaciones en crisis, escritura de informes para presentar en el Tribunal y destrezas en testificar en el Tribunal. Estas son destrezas básicas y esenciales para una intervención efectiva y eficiente.

4. Que el personal que va a atender la situación del/la menor que haya sido removido/a realice su intervención a la mayor brevedad posible. La misma debe ser intensiva, progresiva y muy frecuente durante las primeras dos (2) semanas. De ser así, ese profesional podrá tener rápidamente un cuadro general de la situación (necesidades) y podrá inmediatamente poner en ejecución el Plan de Servicios. Además, podrá rápidamente tener una percepción preliminar del pronóstico de la situación y así comenzar a realizar los planes de permanencia concurrentes (se hacen cuando la familia no responde al Plan de Servicios y establecen un Plan diseñado para el/la menor para ser implantado simultáneamente con otras alternativas para garantizar la estabilidad y sentido de permanencia de éste). No se pierde de perspectiva que la ley establece que el trabajador social o técnico es quien recomienda las acciones finales en las situaciones asignadas.

5. Que los jueces o juezas estén conscientes del término de tiempo establecido en la Ley para el proceso de intervención y los resultados esperados: reunificación o permanencia en otro hogar del/la menor. En muchas ocasiones, a veces por tecnicismo, la determinación del juez puede prolongar la situación por un período de tiempo considerable, lo cual redunda en mantener activa dicha situación en el Departamento de la Familia. Reconocemos que el Tribunal tiene una responsabilidad muy seria en la determinación del mejor bienestar del/la menor, pero sin embargo, se deben evitar los procesos burocráticos, para así agilizar los resultados en pro del mejor bienestar de la niñez.

6. Que durante el proceso interventivo se le ofrezca especial atención a los/as menores que hayan sido removidos de su hogar. Es necesario que esto forme parte del Plan de Servicios, ya 
que el solo ubicar a un/a menor en un hogar sustituto o albergue no elimina las huellas profundas del maltrato vivido por estos/as niños/as. Es por eso importantísimo y necesario que estos indefensos niños/as reciban una atención y servicios muy especializados para aminorar los efectos dañinos del maltrato o negligencia.

7. Que el trabajador social o técnico sea más diestro y "agresivo" en la utilización de otras metodologías existentes en trabajo social, además de la intervención individual (uno a uno), tales como: el trabajo con grupos pequeños y la intervención a nivel familiar y comunitaria. Existen grandes beneficios en la utilización de la metodología grupal. Entre estos están:

a) se ahorra tiempo y esfuerzos,

b) se llega a un número mayor de personas,

c) y además los grupos sirven de apoyo a los participantes, entre otros.

Me resta concluir que se quiera o no, con fallas y beneficios, la Ley 342 ya está en vigor. Es ahora responsabilidad de todos observar que la misma se cumpla en pro del mejor bienestar para nuestros/as niños/as. Además, debemos de continuar siendo críticos ante la aplicabilidad de la Ley y recordar que en nuestras manos existe un mecanismo que se llama enmiendas.

\section{Referencias}

González, E. (1999). Ponencia Proyecto de la Cámara de Representantes Número 2830, Ley para el Amparo a Menores en el siglo XXI. San Juan, P.R. 5 de noviembre.

Ley 342 - Ley para el Amparo a Menores en el siglo XXI, 16 de diciembre de 1999. San Juan, P.R.: Cámara de Representantes.

Nevares de Rosselló, M. (1999). Ponencia de la Primera Dama frente a la Comisión de lo Jurídico Civil, Cámara de Representantes. Oficina de la Primera Dama, 5 de noviembre. 
Pransky, J. (1980). Prevention: The Critical Need. Springfield: Burrell Foundation.

Rivera Watterson, M. y Marrero, Aulet, D. (1999). Posición del Colegio de Trabajadores Sociales de Puerto Rico al Proyecto de la Cámara 2830. San Juan, P.R.: Colegio de Trabajadores Sociales.

Rodríguez-Burns, F. (2002). Asegura el Departamento de la Familia: Ahora es más fácil adoptar. Primera Hora, San Juan, P.R. 8 de enero.

Rodríguez-Burns, F. (2002). Con paso lento la adopción. Primera Hora, San Juan, P.R. 8 de enero.

Rodríguez, M. (1999). Será delito no informar sobre el maltrato. El Nuevo Día. San Juan, P.R. 24 de octubre.

Santana, M. (1999). Maga impulsa nueva ley de protección a menores. El Nuevo Dia. San Juan, P.R. 27 de octubre.

Torres Gotay, B. (2001). Burocracia que no apoya a los niños. El Nuevo Día, San Juan, P.R., 5 de mayo.

Varela Llavona, A. (1999). Ponencia Proyecto de la Cámara 2830. San Juan, P.R.: Departamento de la Familia, 2 de noviembre.

Villanueva Muñoz, E. (1999). Informe del Colegio de Abogados a la Comisión de lo Jurídico Civil de la Cámara de Representantes sobre el P. de la C. 2830. San Juan, P.R.: Colegio de Abogados de Puerto Rico, 8 de noviembre. 
